\title{
Consideraçōes sobre problemas florestais da Amazônia Brasileira
}

\author{
Jurandyr da Cruz Alencar * \\ Luís Mauro Sampaio Magalhães * \\ Arthur Araújo Loureiro *
}

Dados recentes mostram que a floresta de terra firme cobre aproximadamente $90 \%$ da região, onde se encontra uma riqueza imensa de madeiras ainda praticamente inexploradas. Essa enorme área ven, nos últimos anos, sofrendo uma forte pressão populacional e de exploração dos seus recursos florestais, notadamente da madeira, não só devida às indústrias madeireiras que estão se instalando, como pela implantação, em larga escala, de empreendimentos agropecuários com gado bovino.

Bruce (1976) informa, que somente no ano de 1972, foram extraídos da floresta amazônica um volume de 3,29 milhões de metros cúbicos de madeira roliça para utilização pelas indústrias de serrarias, compensado e laminado ou para exportação em toras. Dada a expansão da indústria madeireira após 1972. acredita-se que o volume que se extrai das florestas amazônicas, nos dias atuais, deva ser superior a $6.000 .000 \mathrm{~m}^{3}$ de madeira roliça. Sabemos, também, que todo esse volume é extraído de forma primitiva e rudimentar nas florestas de várzeas, ao longo dos rios e igarapés.

Exploração madeireira mecanizada das florestas de terra firme para abastecimento das indústrias e exportação é inexistente na Amazônia brasileira. Apenas algumas serrarias estão realizando este trabalho, mas utilizando utensílios e equipamentos inadequados, tais como machados para abate de árvores e tratores agrícolas para arraste de toras, em desa cordo com as modernas técnicas de explora ção florestal.

Recentemente, o Projeto RADAMBRASIL, que procedeu ao levantamento dos recursos naturais da Amazônia, avaliou em 8,7 bilhões de metros cúbicos o potencial existente em madeira, que se comercializado no exterior. daria ao Brasil divisas da ordem de 700 bilhões de dólares (apud Loureiro et al., 1979) .
No momento, em meio às pressões que a região vem sofrendo, há uma ampla discussão, em todos os quadrantes do país, sobre o modo como a floresta pode ser manejada sem causar danos ao sistema ecológico da vasta área. As informações científicas disponíveis no campo do manejo florestal, mesmo dando atenção às já divulgadas pela SUDAM (Superintendência do Desenvolvimento da Amazônia), obtidas em sua Estação Experimental de Curuá-Una e as pesquisas florestais, ecoiógicas e botânicas, que se desenvolvem no INPA (Instituto Nacional de Pesquisas da Amazônia), são ainda insuficientes para uma afirmação definitiva sobre o melhor método de manejo florestal a ser adotado. Entretanto, essas informações nos mostram como é frágil o equilíbrio do sistema ecológico da Amazônia e que esse equilibrio repousa fundamentalmente na floresta. Do modo como se vem processando a exploração das matas, com desmatamentos enormes, serão graves os problemas com erosão e perda de solos. Sabemos também que a rica cobertura florestal que se apresenta de forma exuberante aos olhos de todos é resultado de reciclagem contínua de nutrientes, que vem se processando há centenas de anos, funcionando como se fosse uma esponja que retém a quase totalidade dos elementos minerais. Quando a floresta é destruída, o sistema é rompido, ocasionando sérios proWlemas hidrológicos tais como o aumento e desequilíbrio na vazão dos cursos d'água.

Deste modo, apesar das informações já disponíveis, há ainda uma série de problemas florestais e ecológicos que preocupam a Amazônia, muitos dos quais sem resposta, no momento.

Assim, o presente trabalho se propõe a discutir esses problemas e pontos ainda sujeitos a controvérsias, de modo que contribua para um melhor entendimento do manejo dos recursos florestais desta regiāo. 


\section{MANEJO FLORESTAL}

E por demais conhecido que a floresta tropical úmida, que cobre a região amazônica, é constituída por vários tipos de vegetação, todos eles com uma característica básica em comum, isto é, a grande heterogeneidade da sua estrutura florística.

Loureiro et al. (1979) admitem que existe em toda a Hiléia cerca de 4.000 espécies arbóreas, distribuídas de modo regular em toda a região e que somente na Xiloteca do Instituto Nacional de Pesquisas da Amazônia já estão catalogadas cerca de 1.674 dessas espécies, representadas por 642 gêneros e 114 famílias botânicas. Destas espécies, Rivole (1978), citando Bruce (1976), apresenta uma lista das "madeiras comerciais" na ordem de importância, constituída por apenas 24 espécies, tendo as cinco primeiras, Ucuúba (Virola surinamensis), Andiroba (Carapa guianensis), Louro inhamuí (Ocotea cymbarum), Mogno (Swietenia macrophylla), Cedro (Cedrela odorata) e Sucupira (Diplotropis sp.) apresentado, em 1975, vendas superiores a $50.000 \mathrm{~m}^{3}$. $\mathrm{Em}$ race da heterogeneidade das árvores, um número muito grande de espécies ainda não tem suas propriedades físicas e mecânicas conhecidas. A expansão da indústria madeireira na Amazônia exige que um maior número de madeiras seja tecnologicamente conhecido para, então, partir para a conquista de novos mercados. Há ótimas perspectivas neste sentido, para o futuro, dado o natural esgotamento das reservas florestais da Ásia e Africa. Por isso, laboratórios para o estudo da madeira devem ser instalados na Amazônia para superar essa necessidade, como o existente em Santarém, Pará, da Superintendência do Desenvolvimento da Amazônia. No momento, - INPA está construindo um grande laboratório de produtos florestais, que funcionará a partir de 1981 .

Outro ponto que costuma ser questionado é, qual seria o manejo silvicultural na floresta natural a ser adotado, visando a favorecer o crescimento destas espécles comerciais. A esse respeito seria aconselhável a adoção de dois tipos de manejo. Antes, deve-se considerar que a exploração mecanizada das florestas amazônicas, ou seja, a retirada do volume cơmercial para a formação de uma renda real, é possivel e economicamente viável conforme expuseram Marn et al. (1978). O primeiro método seria após a exploração, e partindo de inventários florestais diagnóstios, conduzir a regeneração natural, favorecendo o desenvolvimento das espécies estabelecidas, que tenham uma densidade satisfatória na área e que apresentem aptidões para vários setores da utilização da madeira. O outro método seria, também após a exploração comercial, o estabelecimento de enriquecimento da área através do plantio de espécies de valor, visando à formação de povoamentos mais homogêneos. Esses plantios estabelecidos sob sombra da floresta primária, devidamente explora$\mathrm{da}$, oferecem menores danos ao sistema ecológico, já que não implicam no corte raso de grandes áreas, além de oferecer proteção ao solo, que não se degrada, dado o período longo de condução. Os resultados com algumas dessas espécies na Reserva Florestal Ducke, INPA, mostram que as tolerantes à sombra, tais como: Cedrorana (Cedrelinga catenaeformis) (Fig. 1), Massaranduba (Manilkara huberi), Pau-rosa (Aniba duckei), Tatajuba (Bagassa guianensis), Jacareúba (Calophyllum angulare), Andiroba (Carapa guianensis), podem ser manejadas segundo esse sistema. Para as espécies heliófilas, que preferem alta taxa de luminosidade para se desenvolverem, tais como: Cedro (Cedrela odorata), Mogno (Swietenia macrophylla), Guariúba (Clarisia racemosa), Angelim pedra (Dinizia excelsa), Acapu (Vouacapoua pallidior) e outras, não é recomendável a adoção destes métodos, tendo em vista os conhecimentos no momento. Para estas espécies, recomenda-se o plantio em plena abertura.

Questiona-se também se é recomendável técnica e economicamente fazer-se o controle fitossanitário na floresta natural da amazônia das espécies comerciais para evitar danos causados por insetos. Os resultados das pesquisas silviculturais que se desenvolvem na Reserva Ducke (INPA), mostram que na floresta primária é baixa a incidência de pragas e nos plantios mistos, sob sombra da floresta primária, esta incidência dè pragas também é pequena em comparação cơm os plantios em plena abertura. Deste modo, o controle fitos- 


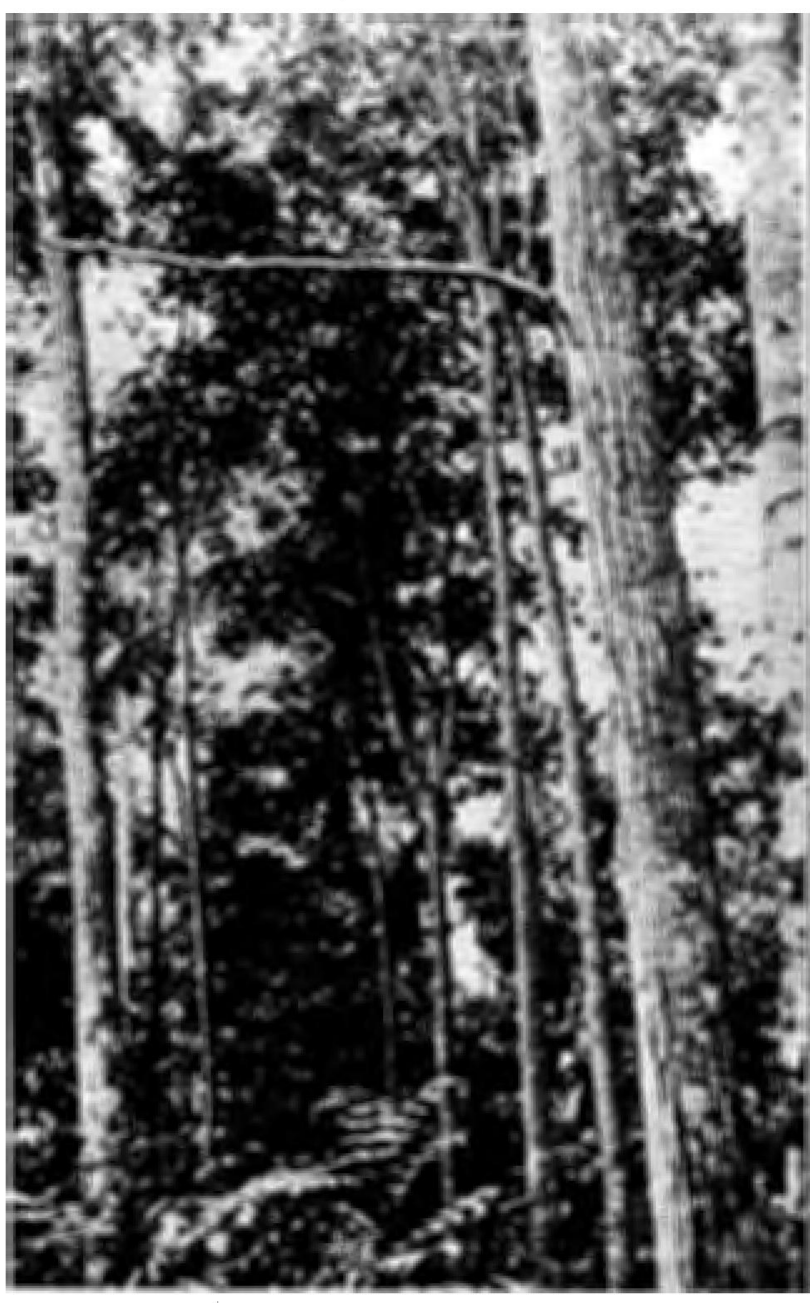

Fig. 1 - Parcela experimental de Cedrorana (Cedrelinga catenaeformis] em plantio de enriquecimento sob sombra de floresta primária. Parcela com 15 anos. (Reserva Florestal Ducke - INPA).

sanitário nestas áreas pode ser feito a um custo reduzido. Nos plantios em plena abertura, o controle deve ser feito com maior intensidade, o que exigirá maior soma de recur. sos.

Outio ponto interessante a considerar é que uma boa parte da madeira provém de áreas que foram desmatadas para cultivos agrícolas. Entretanto, na amazônia, são praticamente inexistentes cultivos agrícolas florestais ou agro-silviculturais como outros denominam. Há pouca experiência sobre estes cultivos. Todavia, é recomendável reforçar os estudos neste sentido. A implantação de povoamentos agrosilviculturais, num sistema multi-estratificado é sumamente recomendável para a Amazônia, em face da sua ecologia com alto índice pluviométrico, solos pobres, passíveis de serem erodidos e com uma alta taxa de lixiviação.

\section{PLANTIOS INDUSTRIAIS}

A regeneração e exploração da floresta amazônica brasileira apresentam grandes perspectivas de estudos e aplicação de técricas silviculturais já determinadas. O Governo brasileiro, atualmente, volta-se com mais atenção para a recomposição e utilização deste imenso potencial madeireiro e, apesar de não dispormos, hoje, de nenhum órgão ligado especificamente à assistência técnica de projetos de reflorestamento, o Instituto Brasileiro de Desenvolvimento Florestal (IBDF), órgão federal de fiscalização e controle dos recursos tlorestais de todo Brasil, é o responsável pela direção técnico-legislativa dos projetos de todo o país. Por outro lado, vários órgãos te. derais têm pesquisado a regeneração de florestas nativas e exóticas da Amazônia, tais como: SUDAM (Superintendência do Desenvolvimento da Amazônia), com base física na Estação Experimental de Curuá-Una, no Pará, EMBRAPA (Empresa Brasileira de Pesquisas Agropecuárias), que vem desenvolvendo, no Estado do Pará, projetos experimentais de reflorestamento e manejo nas regiões de Belterra e Tapajós e INPA (Instituto Nacional de Pesquisas da Amazônia), órgão ligado ao CNPq (Conselho Nacional de Desenvolvimento Científico e Tecnológico), que realiza projetos de regeneração florestal em duas áreas próximas à cidade de Manaus. Algumas destas experimentações já têm dados publicados, propiciando boas indicações para novos estudos e mesmo aplicações práticas (Pedroso, et al., 1971; Volpato et al., 1972 e 1973; Dubois, 1971; Alencar \& Fernandes, 1978; Loureiro et al., 1979).

Em plantios realizados em Curuá-Una, Pedroso (1969) observa um bom desenvolvimento de espécies exóticas sob regeneração artificial, sobrepujando o desenvolvimento observado em algumas espécies nativas. Algumas parcelas de Pinus spp. tiveram bom crescimento em altura e diâmetro, demonstrando boa adaptação às condições locais. Por outro lado, as parcelas de Eucalyptus, após bom desen- 
volvimento inicial, tiveram problemas de adap. tações, sendo que, hoje, seria temerosa qualquer recomendação no sentido de plantarem-se as espécies testadas. Um plantio em escala comercial, realizado pela empresa Jari Florestal, vai fornecer dentro de algum tempo respostas mais precisas para questões referentes a utilizações de essências exóticas na Amazônia brasileira. Toda a prơdução de Gmelina arborea e Pinus caribeae deverá ser utilizada em recém-instalada usina de polpa, sendo que breve estarão sendo cortados os primeiros talhões para industrialização. Também, no INPA, algumas tentativas de introdução de essências exóticas têm sido realizados, sendo que, parcelas de Eucalyptus deglupta (Fig. 2), têm apresentado bom comportamento com a idade de dois anos. Após um maior período de tempo, aquelas parcelas poderão ser meIhor analisadas quanto à sua adaptação ao novo ambiente. Também, a introdução de Nauclea sp. tem sido testada neste Instituto, sendo que a espécie, após bom desenvolvi- mento durante os primeiros dois anos, sofreu um intenso ataque fúngico em suas folhas ocasionando a morte de vários indivíduos (Fernandes, comunicação pessoal). Os espaça. mentos básicos usados nas experimentações são $5 \mathrm{~m} \times 5 \mathrm{~m} ; 10 \mathrm{~m} \times 5 \mathrm{~m} ; 4 \mathrm{~m} \times 3 \mathrm{~m} ; 2,5 \mathrm{~m} \times$ $2,5 \mathrm{~m} X$ e $3 \mathrm{~m} \times 2,5 \mathrm{~m}$ para os diversos sistemas de plantio, sendo que ainda não existem dados suficientes para recomendações precisas destes espaçamentos. Toda a pesquisa florestal é bastante demorada, sendo que para obtermos respostas seguras quanto à adaptação, o desenvolvimento e outras características de espécies para plantio, em condições tropicais úmidas, exige um prazo dilatado de observações para maior segurança. Deve deixar-se claro que, além das variantes silviculturais, devem ser determinados os fatores ecológicos e econômicos envolvidos na produção florestal e estas determinações só são possíveis em espaço de tempo maior.

Por outro lado, vários sistemas silviculturais, visando à recomposição de espécies

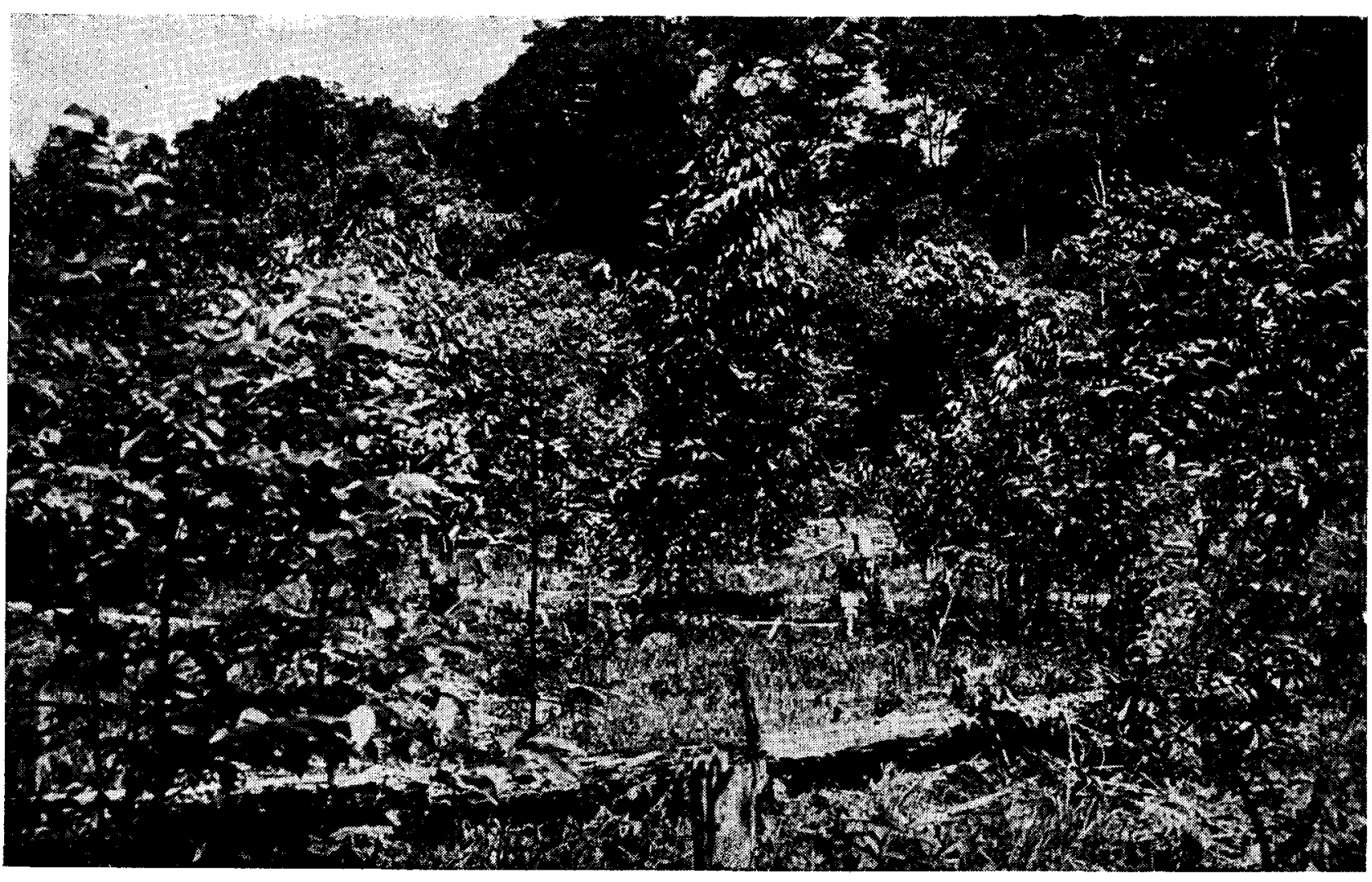

Fig. 2 - Parcela experimental de Eucalyptus sp. em plantio em plena abertura. Parcela com um ano e altura total média de 5 - 6 metros (Estação Experimental de Silvicultura Tropical - INPA). 
nativas amazônicas, têm sido experimentados com resultadios de bom desenvolvimeno, tanto em regeneração natural, como em regeneração artificial. Dubois (1971); em relatório da $F A O$, relaciona várias espécies nativas para plantios em plena abertura e, de enriquecimento, de várias regiões. $O$ autor aponta também um bom potencial para exploração de regeneração natural, baseado principalmente em parcelas estabelecidas em Curuá-Una. Alencar \& Fernandes (1978) e Alencar et al. (1979), apresentam o desenvolvimento de Aniba duckei e Calophyllum angulare sob diversos sistemas e Volpato et al. (1973) em trabalho referente a parcelas experimentais da Reserva Florestal Ducke apontam várias espécies nativas de bom desenvolvimento sob sombra. Em regiões tropicais de alta pluviosidade, 0 corte raso com uso de mecanização pesada é desaconselhável, pois resulta em compactação do solo, com a exposição à insolação direta e às enxurradas anuais, que lavam a camada superficial deste solo (Fig. 3). Desta forma, se houver a possibilidade de serem trabalhadas espécies de bom crescimento, em sombra, nos primeiros anos, estaremos dando, além de uma maior proteção às mudas recémplantadas contra períodos secos, uma grande proteção à camada superficial e mais rica do solo.

Um grande problema encontrado por parte de quem se lança à atividade de recomposição florestal na amazônia brasileira é o de conseguir fornecimento seguro de material propagativo para os plantios. Embora algumas instituições iniciem, hoje, programas de instalação de Banco Regionais de Sementes, a obtenção deste material, principalmente com espécies nativas, se dá de forma improvisada, sem qualquer critério genético. Hoje, uma das saídas seria o investimento de recursos na implantação de cada projeto de reflorestamento, para uma seleção criteriosa de árvores porta-sementes em áreas contíguas às de plantio e em matas primárias. O material coletado destas árvores, além de servir para

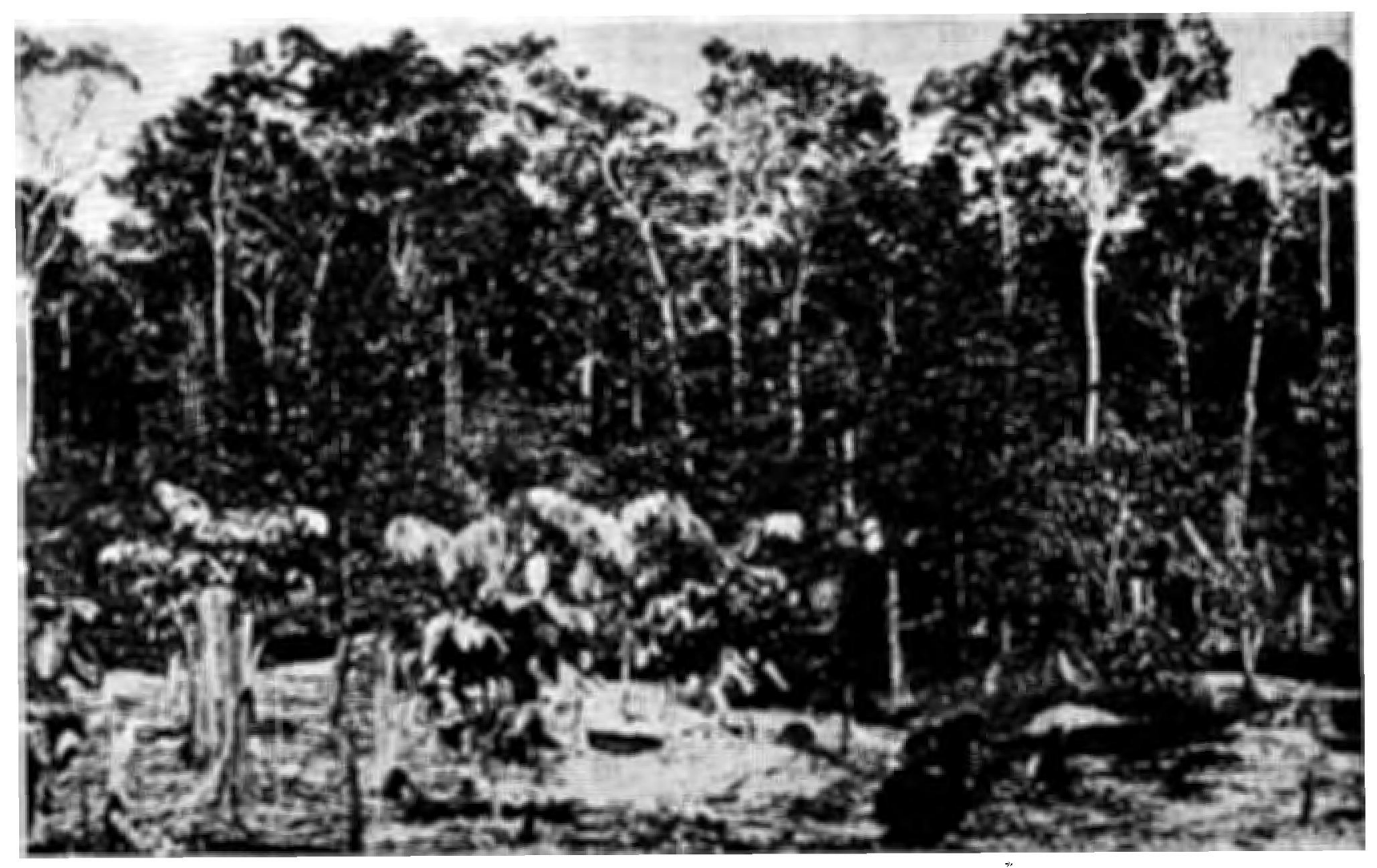

Fig. 3 - Exposição do solo em sistemas de plena abertura um ano após o plantio. Parcelas de Cedrorana (Cedrelínga catenaeformis) (Estação Experimental de Silvicultura Tropical). 


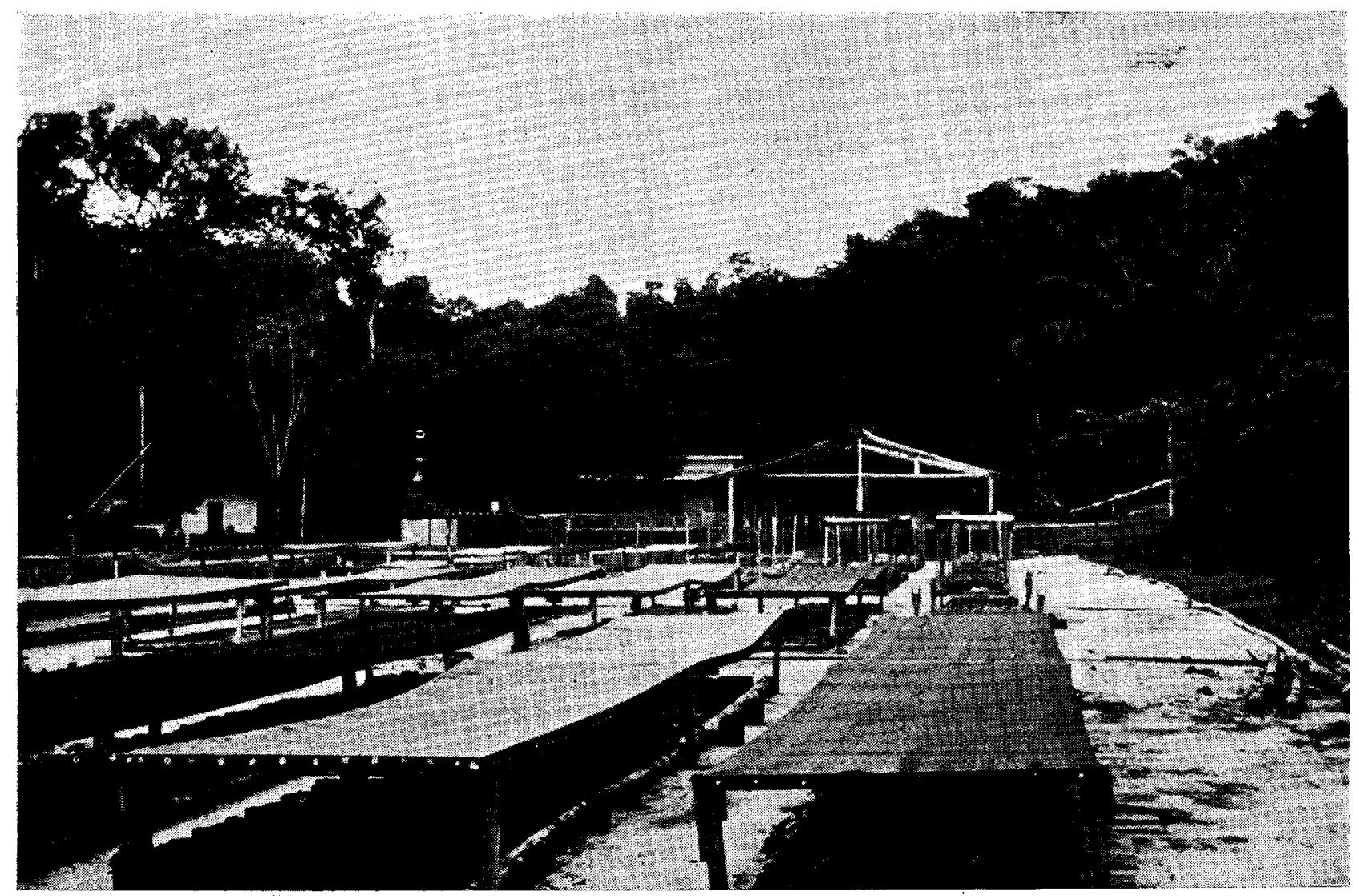

Fig. 4 - Experimentações do comportamento de mudas florestais em diferentes sombreamentos. Viveiro Experimental da Reserva Florestal Ducke.

propagação nos plantios, poderia vir a ter um papel importante em futuros projetos de meIhoramento genético destas essências. Já o fornecimento de sementes de outras regiões do mundo é feito, em geral, a nível de empresas ou órgãos interessados, que buscam o fornecimento deste material em entidades internacionais ou de outros países com possibilidades para tal. Dubois (1971) relaciona alguns destes órgãos, dando ênfase a países de regiões tropicais.

A produção de mudas, em viveiros, para regeneração artificial das fases operacionais de reflorestamento, é das mais suscetiveis a perdas e danos diversos, dependendo de sua boa condução o sucesso das mudas no campo. Por isto, todos os esforços devem ser feitos, de modo que possamos contar com mudas vigorosas e sadias para o plantio definitivo, mesmo que, para isso, seja necessária a aplicação de maiores recursos financeiros nestas operações (Glessinger, 1960 e Deichmann.
1967). Apesar de em algumas essências exóticas, ter-se o conhecimento das condições necessárias para o bom desenvolvimento de suas mudas, em condições de viveiros, muito há que se estudar, em se tratando de essências nativas. O desenvolvimento aéreo e radicular deve ser pesquisado segundo fatores de luminosidade, absorção de nutrientes e necessidades hídricas de cada essência. A utilização de adubação orgânica e ou mineral e o uso de coberturas com taxa de luz adequada são importantes para a obtenção de um desenvolvimento máximo (Fig. 3). Além disto, a utilização de bons recipientes devem ser estudados segundo as diversas alternativas. Recipientes de polietileno, apesar de serem mais caros e obtidos a partir de petróleo, têm demonstrado ótima versatilidade, fácil manuseio e boa resistência à decomposição. Em certo's casos, as mudas devem permanecer por período de tempo maiores no viveiro, o que não é possível se o recipiente se decom- 
põe com a insolação e chuvas fortes em pouco tempo. Por outro lado, apesar de, no plantio com raiz nua, serem eliminados todos os tratos culturais necessários na utilização de recipientes, estes últimos garantem às mudas recém-plantadas mais fácil adaptação ao novo meio, bem como melhores condições para pleno estabelecimento de novo sistema radicular. Devem ser avaliadas para cada espécie e, nas diversas regiões, as possibilidades e os problemas referentes às duas técnicas.

Concluindo, pode-se afirmar que os problemas técnico-científicos que atingem a indústria florestal na Amazônia, além dos apresentados, são de natureza complexa e conseqüências do próprio processo de desenvolvimento regional, que ainda hoje se apoia numa economia pré-capitalista. Entretanto são boas as perspectivas para o futuro e espera-se uma gradativa expansão da atividade florestal na Amazônia, de modo harmonioso, já que ela é a última grande reserva tropical de produtos naturais disponível no mundo.

\section{BIBLIOGRAFIA}

Alencar, J.C. \& Fernandes, N.P.

1978 - Desenvolvimento de árvores nativas em ensaios de espécies. I. Pau rosa (Aniba duckei Kostermams). Acta Amazonica, 8(4): 523-541.

Alencar, J.C.; Loureiro, A.A. \& Fernandes, N.P.

1979 - Desenvolvimento de árvores nativas em ensaios de espécies. 2. Jacareúba (Calophyllum angulare A.C. Smith). Acta Amazonica: (no prelo).

BRUCE, R.W.

1976 - Produção e distribuição da madeira amazónica. Série Estudos, PRODEPEF, PNUD, FAO, IBDF, BRA-45. 90p.
DeICHMANN, V. VoN

1967 - Noções sobre sementes e viveiros florestais. FAO. Escola de Florestas. Universidade do Paraná. 196 p. il.

DuBoIs, $\mathbf{J}$.

1971 - Silvicultural research in the Amazon. FAO, FO, SF/BRA-4, Technical Report 3.

Glessinger, E.

1960 - Practicas de plantacion forestal en America Latina. FAO, Roma. 499 p. il.

Loureiro, A.A.; Silva, M.F. DA \& Alencar, J.C.

1979 - Essências madeireiras da Amazônia. Vol. I e II. INPA. Patrocínio da Superintendência da Zona Franca de Manaus - SUFRAMA.

Marn, H.M.; Lejonstahl, R.; Yared, J.A.G. et AL. 1978 - Estudo de viabilidade técnico-econômica da exploração mecanizada em floresta de terra firme. Região Curuá-Una. SUDAM PNUD/FAO/IBDF/BRA-76/027.

Pedroso, L.M.

1969 - Informaçōes sobre o atual comportamento de espécies exóticas na região do Baixo Amazonas. SUDAM, 5(1/4) : 23-32.

Pedroso, L.M.; Pereira, A.P.; Leite, P.F. \& Silva, C. da 1971 - Informações preliminares sobre a silvicultura de 38 espécies florestails da Estação Experimental de Curuá-Una. SUDAM, APC. D.D.

Rrvole, G.

1978 - Informes sobre a comercialização de madeira amazônica. In: desenvolvìmento e planejamento florestal. Ministério da Agricultura, COPLAN, Série Técnica 7 .

Volpato, E. Schmidt, P.B. \& Araujo, V.C.

1972 - Carapa guianensis Aubl. (Andiroba). Estudos comparativos de tratamentos silviculturais. Acta Amazonica, 2(3) : 75-81.

1973 - Situação dos plantios experimentais na Reserva Ducke. Acta Amazonica, 3(1): 71-82. 